\title{
How to Protect Children from Covid-19 Pandemic?
}

ISSN: 2576-9200

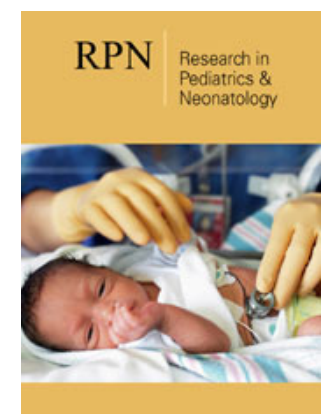

*Corresponding author: Jayanthi P, Shri Sathya Sai College of Nursing, Sri Balaji Vidyapeeth Deemed to be University, Chennai, India

Submission: 望 July 24, 2020

Published: 侮 August 13, 2020

Volume 4 - Issue 5

How to cite this article: Jayanthi P. How to Protect Children from Covid-19 Pandemic?. 4(5). RPN. 000597. 2020. DOI: 10.31031/RPN.2020.04.000597

Copyright $\subseteq$ Jayanthi P. This article is distributed under the terms of the Creative Commons Attribution 4.0 International License, which permits unrestricted use and redistribution provided that the original author and source are credited.

\section{Jayanthi $\mathrm{P}^{1 *}$}

Faculty of Nursing, Shri Sathya Sai College of Nursing, Sri Balaji Vidyapeeth Deemed to be University, India

\section{Introduction}

Coronavirus disease (COVID-19) pandemic is a major health crisis affecting several nations. Children have been regarded as the nation's supremely important asset. They already suffer from the public health crisis of malnutrition and pneumonia and COVID-19 endangers them further. It is our responsibility to act and mitigate the hidden adverse impact that this pandemic threatens our children with for their brighter future. The reported cases of COVID 19 are comparatively less to children than adults and geriatric with co-morbid illness like hypertension and diabetes mellitus. Children in India to be at higher risk due to malnutrition, environmental pollution and accessibility and availability of medical care. Hence, this is a new virus and we need to learn more about how it affects children.

Children affected with COVID-19 can fall into four categories:

a. Asymptomatic infection

b. Acute upper-respiratory-tract infection

c. Mild pneumonia and

d. Severe pneumonia [1].

\section{Know the Latest Facts \& Information}

Parents have to provide basic information about symptoms, transmission, complications and prevention of transmission of coronavirus disease (COVID-19). Convey COVID-19 reliable information from reputable sources such as World Health Organization (WHO), United Nations International Children's Emergency Fund (UNICEF) and National Health Ministry Advisories. Correct facts about COVID-19 will help to reduce child's fear and anxieties about the disease.

\section{Plan for Continuity of Learning}

COVID-19 affected the education of the children. Now many schools started virtual learning for the students. Parents and children are familiar with traditional learning methods and evaluation strategies. In class room teaching, teachers had control over their students. Parents has to monitor their children during online classes, help them to complete the assigned reading and exercises for home study and do not allow the children to access the unwanted websites.

\section{Address Mental Health/Psychosocial Support Needs}

COVID -19 made the children to be home bound which in turn causes stress, anxiety and frustration among them. Children may respond to stress in different ways. Some children experience sleeping difficulty, bedwetting, stomach ache or head ache, anxiety, withdrawal behavior and anger. Parents have to aware of their children's symptoms, comfort them and give them affection. Play with your children and relax. Parents have to follow regular schedules and praise your children [2]. 


\section{Tips to Parents}

1. Monitor your child's health

2. Teach good hand hygiene / good respiratory hygiene

a. Wash hands with soap and water frequently.

b. If soap is not available, use an alcohol-based hand sanitizer.

c. Cough or sneeze into a clean tissue.

d. Dispose the tissue immediately into the nearest waste bin.

e. If you do not have a tissue, cough or sneeze into elbow.

f. Always clean hands after coughing or sneezing, either using soap and warm water or alcohol handrub or hand wipes.

g. Teach social distancing (standing further away from friends, avoiding large crowds, not touching people if you don't need to, etc).

3. Understand your child's reaction to stress

4. Listen to child's concerns and answer their questions.

5. Explain to your child what is happening in simple words and reassure them that they are safe.
6. Spend quality time with your children

7. Know more about their interest, hobbies, friends and life goals.

8. Encourage them to drink 8-10 glasses of water and eat balanced diet.

9. Encourage them to do prayers regularly.

10. Allow them to practice yoga or meditation.

11. Avoid watching television and using electronic gadgets for longer time.

12. Share your experiences, achievements and challenges encountered in your life [3].

\section{References}

1. Rajkumar RP (2020) COVID-19 and mental health: A review of the existing literature. Asian J Psychiatr 52: 102066.

2. WHO (2020) Helping children cope with stress during the 2019-nCoV outbreak. World Health Organization, Switzerland, Europe.

3. UNICEF (2020) Key messages and actions for COVID-19 prevention and control in schools, New York, USA. 